\section{Special FANTOM2 Issue}

It is my great pleasure to be able to publish a special issue of Genome Research focusing on the functional annotation of mouse cDNA (FANTOM). Publication of this FANTOM special issue is quite timely, as not only the mouse full-length cDNA collection but also the first draft of mouse genome sequences were just published at the end of last year. Moreover, completion of the human genome sequence was announced this spring and entered the next phase. This is a very exciting series of events. In the history of life sciences, the mouse is the first organism for which large-scale analyses of the genome and transcriptome were undertaken at the same time. This data will form the basic platform of life sciences in the 21st century. In this issue, we present papers on FANTOM activity, describing analyses based on the first data for the genome and transcriptome.

The international FANTOM consortium was established to annotate functions for sequences in the full-length cDNA sequence database, which was developed by the Riken Mouse Gene Encyclopedia Project. The background of this project should first be explained.

The project was started in 1995 and originally aimed at the overall collection of full-length cDNAs for all genes supported by the Science Technology Agency (currently the Ministry of Education, Culture, Sports, and Technology [MEXT]). At that time, the international human genome consortium started large-scale sequencing analysis of the entire human genome, and the EST project was almost saturated. Under circumstances in which genome science was rapidly gaining prominence in the world, we faced the following question: "What significant contribution would Japan make to this scientific field?" Our answer was mouse full-length cDNA.

We started this mouse gene encyclopedia project by developing original technologies for full-length cDNA library preparation and a high-throughput system for sequence determination. Our system, the RIKEN integrated sequence analysis (RISA) system, achieved throughput of 40,000 samples per day, facilitating the establishment of the largest collection of full-length cDNAs for the mouse in the world. The full-length cDNA library was prepared by Spring 2000 from 263 tissues, finishing sequence analysis of 60,770 clones in total with full sequences selected from about 2 million end-sequenced clones in Summer 2001. After determining full-length cDNAs, functional annotation of these clones required the kind of enormous effort that can only be achieved with worldwide cooperation. We contacted researchers from various fields of biology and advertised in journals and on the Internet, opening our meetings to anyone who wished to participate, contribute, and help. Many researchers agreed with the goal of founding an international de facto standard of well-annotated full-length cDNA resources, and they volun-

Article and publication are at http://www.genome.org/cgi/doi/10.1101/ gr.1400103. tarily joined the FANTOM consortium. We greatly appreciate the dedication of the more than 80 researchers in FANTOM1 and 100 researchers in FANTOM2.

Integrated analysis of the genome and transcriptome created a synergistic effect, providing extremely valuable insights into the nature of life. The transcriptome provides the exact location of genes, whereas genome sequences provide information such as promoters and exon-intron junctions. Analyses of the mouse genome sequence and 60,770 mouse transcripts were fortunately completed at the same time, with results published late last year. After publication, further studies by the FANTOM consortium based on the enormous amounts of data aimed for systematic understanding of the mouse transcriptome as a model for the human system, and they form the contents of this special issue.

One notable feature of this special issue is a new proposal for clone transportation. With the development of genome science, handling of numerous clones as a platform for research has become indispensable. A new type of transportation system to facilitate such handling has long been warranted. The proposal described herein, in a paper entitled "DNA Book," may well represent a timely solution, and is expected to work very effectively. The DNA book forms an easily transposable bank of full-length cDNA clones printed on paper and bound like a book, and DNA is actually incorporated onto paper that is included in this report. This issue marks the first large-scale trial of the technique, and the cooperation of subscribers worldwide with this project would be deeply appreciated. Subscribers can get involved by filling out the feedback form at the end of this issue for submission to the URL provided. We would like to report the results of subscriber feedback and assist in further improvements to this new technology. RIKEN and others who are concerned with the large-scale distribution of clones hope that the DNA book will offer a new standard of clone distribution that will soon see practical use.

Lastly, we wish to thank Dr. Wada, Dr. Kurihara, the RIKEN executive committee, and the RIKEN Yokohama promotion office for their administrative support and understanding regarding the importance of this issue. We would also like to thank Dr. Muramatsu for his scientific advice, as well as DNAform and Five Prime Therapeutics for financial support in publishing this special issue.

We sincerely hope our activities provided here can make a contribution to the progress of science.

Yoshihide Hayashizaki Scientific management of FANTOM consortium Project director for RIKEN mouse genome

encyclopedia initiative 


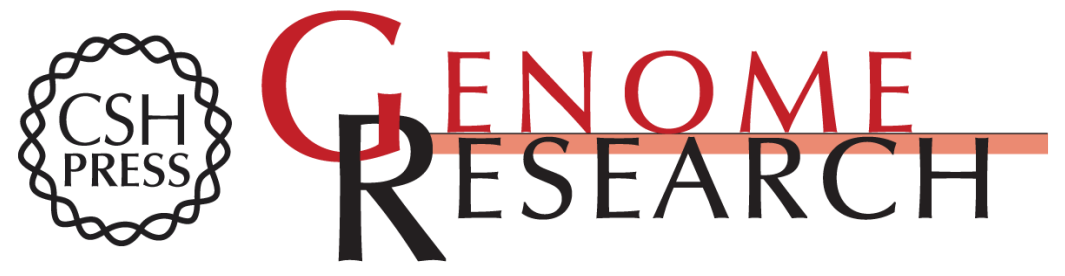

\section{Special FANTOM2 Issue}

Yoshihide Hayashizaki

Genome Res. 2003 13: 1265

Access the most recent version at doi:10.1101/gr.1400103

\section{License}

Email Alerting Receive free email alerts when new articles cite this article - sign up in the box at the Service top right corner of the article or click here.

\section{Affordable, Accurate Sequencing.}

To subscribe to Genome Research go to: https://genome.cshlp.org/subscriptions 